\title{
Waiting list statistics. III. Comparison of two measures of waiting times
}

\author{
B DON, A LEE, M J GOLDACRE
}

\begin{abstract}
The length of time that patients spend on waiting lists is a topic of current concern. Calculating the proportion of patients who have been on a waiting list for a long time by taking a census of patients on the list at a single point in time will tend to yield a higher estimate than that obtained by calculating waiting times of patients admitted to hospital during a period of time. To illustrate this point the waiting times of patients in the Oxford region as measured by SBH 203 returns ("census" data) were compared with those as measured by the Hospital Activity Analysis ("event" data). As expected, the SBH 203 census returns showed a higher proportion of patients who had waited over a year compared with the "event" measure of all admissions.

This difference, which is analagous to the difference between prevalence and incidence in epidemiology, should be considered when using data from these sources to calculate waiting times.
\end{abstract}

\section{Introduction}

Several publications have pointed out that in some districts up to $40 \%$ of patients on the waiting list at a given point have waited for longer than a year for admission. ${ }^{12}$ Such figures should not, however, be taken to indicate that $40 \%$ of patients newly placed on the waiting list during the same period may have waited for more than a year for admission.

\section{Methods}

Routine statistical returns every six months on waiting times for admission to hospital, the SBH 203 returns, provide data enumerating patients on the waiting list at a census point in time by specialty and district. The returns are subdivided into patients who require urgent treatment who have waited for more than a month and those who have waited for one month or less and patients who require non-urgent treatment who have waited for less than a year and those who have waited for a year or more. For patients who have been admitted to hospital from the waiting list, data from the Hospital Activity Analysis can be used to identify the precise duration of time spent on the waiting list by each patient admitted during a period of time.

\section{Results}

As a theoretical illustration, the figure schematically depicts the duration of time spent on the waiting list by individual patients. Two census points, $A$ and $B$, represent the biannual SBH 203 counts. A substantial proportion of the patients at times $A$ and $B$ have waited a long time. Considering the total number of patients admitted between times $A$ and $B$, however, a much smaller proportion of the total have had long waits. It is evident that a patient who has waited for a long time has a higher probability than a patient who has waited for a short time of being present on a given census date.

As a practical example, the table compares data from five districts in the

Oxford Regional Health Authority, Headington, Oxford OX3 7LF

B DON, BSC, DPHIL, regional statistician

Unit of Clinical Epidemiology, University of Oxford, Headington, Oxford OX3 7LF

A LEE, MB, FFARACs, World Health Organisation training fellow

M J GOLDACRE, BM, FFCM, director

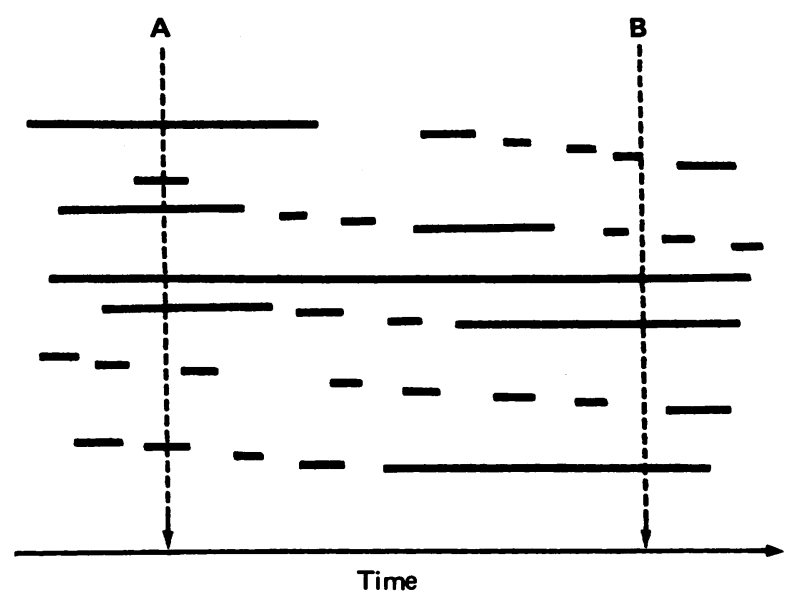

Comparison of census measures (A and B) (from SBH 203 returns) and event measures (from Hospital Activity Analysis) of waiting times. Each horizontal line represents a patient's duration of wait from date of placement on waiting list to date of admission to hospital.

Oxford region. The SBH 203 figures give the proportion of patients who were on the waiting list at the end of September 1983 and who had been on the waiting list for more than 12 months. The data from the Hospital Activity Analysis show the proportion of patients discharged during the calendar year 1983 who had been on the waiting list for more than 12 months. The data show both the magnitude of difference that can exist between the two measures and the fact that within each specialty the ranking of districts may differ depending on which of the two statistical measures is used.

Percentage of patients waiting for more than 12 months from placement on waiting list to admission (from Hospital Activity Analysis data) and on September 1983 waiting list census (from SBH 203 returns) ${ }^{\star}$

\begin{tabular}{ccccccc}
\hline & \multicolumn{2}{c}{ Ear, nose, and throat } & \multicolumn{2}{c}{ Plastic surgery } & \multicolumn{2}{c}{ Gynaecology } \\
\cline { 2 - 7 } District & $\begin{array}{c}\text { Hospital Activity } \\
\text { Analysis }\end{array}$ & $\begin{array}{c}\text { SBH } \\
203\end{array}$ & $\begin{array}{c}\text { Hospital Activity } \\
\text { Analysis }\end{array}$ & $\begin{array}{c}\text { SBH } \\
203\end{array}$ & $\begin{array}{c}\text { Hospital Activity } \\
\text { Analysis }\end{array}$ & $\begin{array}{c}\text { SBH } \\
203\end{array}$ \\
\hline 1 & 46.4 & 36.4 & 18.7 & 59.2 & 5.7 & 17.5 \\
2 & 12.5 & 32.2 & 22.1 & 51.8 & 1.1 & 24.1 \\
3 & 7.7 & 35.8 & $\dagger$ & $\dagger$ & 2.8 & 42.3 \\
4 & 1.3 & 0.0 & $\dagger$ & $\dagger$ & 11.7 & 63.3 \\
5 & 9.7 & 21.9 & 28.5 & 58.7 & 8.0 & 17.7 \\
\hline
\end{tabular}

*We assumed that all "urgent" cases waited for fewer than 12 months. This is necessary to allow comparison with the Hospital Activity Analysis, which does not classify cases as urgent/non-urgent.

†No plastic surgery undertaken in these districts.

\section{Discussion}

The census measure of "patients on the waiting list at a given point in time" identifies a disproportionately high proportion of patients who have waited for a long time compared with the "event" measure of all admissions during one year. The difference between the census and the event measures is of course equivalent to the difference between the measures of prevalence and incidence in epidemiology. ${ }^{3}$ It is the measure of incidence rather than prevalance that should normally be used to quantify individual chances and risks. For example, of the patients admitted from the waiting list for 
gynaecological treatment in district 3, about $3 \%$ had had to wait for more than a year (the Hospital Activity Analysis figure), which contrasts with a " $42 \%$ risk" of waiting for more than a year after placement on the list, which the SBH 203 figure might erroneously be taken to imply.

It should also be noted that the use of the census figures as a basis for "shopping around" between districts" may sometimes be misleading. If a prospective patient for gynaecological treatment in district 3 were referred to district 1 for a shorter wait on the basis of comparing the SBH 203 figures she would in fact be twice as likely to have to wait for more than a year than if she were placed on the waiting list in district 3 .

The SBH 203 and Hospital Activity Analysis figures are not comparable in several respects. Firstly, by definition, data from the Hospital Activity Analysis relate to the full time between placement on the list and admission while the census figures relate only to the time waited so far (neither include the time waited from initial referral to placement on list). Secondly, the census figures probably include patients who will never be admitted from the waiting listfor example, those who are admitted as emergencies or die before their elective admission would have occurred. ${ }^{4}$ Thirdly, no data of placement on the booking list is recorded in the Hospital Activity
Analysis; thus booked admissions, included in the SBH 203 shown in the table, cannot be included in the Hospital Activity Analysis figures. Booked cases, however, made up only about one tenth of elective admissions in the districts described. They are unlikely materially to affect the patterns of waiting shown in the table and do not affect the principles illustrated by the figure. The main difference between the measures of waiting times given by SBH 203 and those given by the Hospital Activity Analysis is the distinction between the census measures and the event measures illustrated in the figure.

\section{References}

1 Department of Health and Social Security. Reduction of waiting times for in-patients admission: management arrangements. London: DHSS, 1975. (HSC (1S)181.)

2 College of Health. The College of Health guide wo hospital waiting lists. 2nd ed. London: Victoria Park Publications, 1985.

3 MacMahon B, Pugh TH. Epidemiology: principles and methods. Boston: Little, Brown and Co, 1970:65.

4 Lee A, Don B, Goldacre MJ. Waiting list statistics. II. An estimate of inflation of waiting list length. BrMed J 1987;295:1197-80.

(Accepted 11 August 1987)

\title{
Research Policy
}

\section{Why do research and which research to do?}

\author{
RICHARD SMITH
}

People do research largely because "it turns them on, because it's there." They often cannot say more exactly why they do it, but rarely is it for financial reward or for Freud's "fame and the love of beautiful women." There are much quicker routes to such rewards. Research can be highly creative, rewarding, and exciting but also intensely frustrating. Those who commit their lives to it are varied, mercurial, brilliant, and strong and single minded, and, recognising this, the policy of many of those funding research (including the Medical Research Council' ${ }^{1}$, has been to spot brilliant researchers and let them do what they want.

Just this year Johnson and Johnson have given Sir James Black, the scientist who discovered $\beta$ blockers and cimetidine, what Sir James calls "distortion free funding." The company will play no part in directing the research but will have first refusal on any products that emerge. Sir James believes that big fanfares and publicity drives interfere with the process of research. Attempts by those who fund research to be too directive may backfire.

Yet governments the world over are becoming much more interested in managing and directing research, ${ }^{3}$ and Britain is no exception. Here I look at why the government and some of the funding bodies support research and at which categories of research they choose to support. These bodies can usually answer the question, "Why do research?" more explicitly and confidently than the people who actually do it. Whether the official bodies can transmit their reasons to the researchers themselves is more doubtful.

British Medical Journal, London WC1H 9JR

RICHARD SMITH, BSC, MB, assistant editor

\section{Why the government supports research}

The government's standard reasons for supporting research were given most recently in its response to the House of Lords Select Committee on Science and Technology's report on civil research and development"; "Public expenditure on science and technology serves various government objectives: the advancement of knowledge, support for policy for formulation and implementation, improvement of technology, improvement of health and the environment, support for procurement decisions and support for statutory duties." These reasons are expanded in an annex to the Annual Review of Government Funded RED (see box) ${ }^{6}$ and in the review the government goes so far as to break down its overall expenditure ( $\$ 4582 \mathrm{~m}$ in $1985-6$ ) according to purpose (fig 1 ).

Comparing the breakdown of expenditure by purpose and where the money actually goes (fig 2 ) gives an idea of the government's real priorities. Obviously defence is at the top, and the Ministry of Defence does no research that the government categorises as basic (see box). Although the British government now spends a much higher proportion of its research funds on defence than most other countries, ${ }^{7}$ the history of government interest in science shows clearly that the military possibilities are usually what first prompts most governments to invest in research. ${ }^{8}$ The first government ever to invest in scientists was the revolutionary government that took power after the French revolution, and the first job of the Committee of Four Citizens was to seek out new methods of defence. More recently it was experience with developing the atomic bomb that led the American government to invest heavily in research for the first time.

The next priority of the British government in conducting research is economic, and the government said in its response to the 